\title{
Os Caminhos do Desenvolvimento no Turismo: o deslocamento da abordagem centralizada na renda para a abordagem com foco nas pessoas
}

\section{The paths of Tourism Development: the displacement of the income centralized approach to a people focused approach}

\author{
Renata Mayara Moreira de Lima (LIMA, R. M. M. de)* e \\ João Bosco Araújo da Costa (COSTA, J. B. A. da)
}

RESUMO - A relação desenvolvimento $x$ turismo não é clara e não pode ser estabelecida apenas com base em dados quantitativos. Levando isso em consideração, o artigo parte do entendimento da necessidade de pensar em novas conexões entre o binômio turismo e desenvolvimento, com a pretensão de contribuir para a consubstanciação de uma discussão balizadora do que se entende por desenvolvimento induzido pela atividade turística. Nessa perspectiva, objetiva-se apresentar os princípios orientadores do que pode ser considerada uma leitura ética do desenvolvimento no turismo. Para isso realizou-se a articulação do desenvolvimento entendido como expansão das capacidades e liberdades dos indivíduos - o desenvolvimento como liberdade - com o turismo, buscando mostrar de que forma é possível, esse fenômeno social, enquanto atividade econômica, contribuir para a transformação social. Ao fim das argumentações chegou-se à conclusão de que entender e trabalhar em prol do que se espera e do que se quer alcançar com a atividade turística para uma determinada sociedade é o primeiro passo para que esta se constitua com potencialidade para a transformação social, sendo fundamental a cooperação entre os diversos atores do turismo.

Palavras chave: Turismo-desenvolvimento; Abordagem; desenvolvimento como liberdade.

ABSTRACT - The relationship between tourism and development is not clear and it cannot be established basically on quantitative data. Taking this into account, this paper was built on the understanding the need in thinking new connections between the tourism and development, looking for the enrichment of the discussion about the meaning of the induced development by tourism. In this point of view, the aim is to present the guiding principles of what can be considered an ethical reading about

\footnotetext{
* Formação: Graduação em Turismo (Bacharelado) pela Universidade Federal do Rio Grande do Norte (UFRN), Mestrado em Ciências Sociais pelo Programa de Pós-Graduação em Ciências Sociais da UFRN. Doutoranda em Ciências Sociais pelo Programa de Pós-Graduação em Ciências Sociais da UFRN. Endereço físico para correspondência: Avenida Senador Salgado Filho, s./n. - Lagoa Nova - Prédio do CCHLA, Sala 430. CEP: 59078-970 - Natal - Rio Grande do Norte (Brasil). Telefax: (084) 3215-3556 e (084) 3215-3559. E-mail: renatammlima@gmail.com

** Formação: Graduação em Ciências Sociais pela Universidade Federal do Rio Grande do Norte (UFRN), Mestrado e Doutorado em Ciências Sociais pela Pontifícia Universidade Católica de São Paulo (PUC-SP). Atividade profissional: Professor associado da Universidade Federal do Rio Grande do Norte no curso de graduação em Ciências Sociais e na Pós-Graduação em Ciências Sociais. Endereço físico para correspondência: Avenida Senador Salgado Filho, s./n. - Lagoa Nova - Prédio do CCHLA, Sala 430. CEP: 59078-970 - Natal - Rio Grande do Norte (Brasil). Telefax: (084) 3215-3556 e (084) 32153559. E-mail: joaobac@uol.com.br
} 
development in tourism. The development, as expansion of individual capacities and free will - development as freedom - was articulated with tourism, seeking to show how this social phenomenon is possible, as economic activity, contribute to social changes. The conclusion is that understanding and working for what we want to achieve with the tourist activity in a particular community is the first step to turn that in a potentiality for social transformation, being essential the cooperation among different actors of tourism.

Key words: Tourism-development; Approach; Development as freedom. 


\section{INTRODUÇÃO}

O estudo do turismo no meio acadêmico sempre esteve atrelado às discussões em torno do desenvolvimento, das políticas públicas e dos retornos (principalmente econômicos) que essa atividade propicia às regiões receptoras. Contudo, esse não tem sido um debate simples, pode-se dizer que principalmente por duas razões: 1) o desenvolvimento, não é como as pessoas poderiam supor, desvinculado de disputas ideológicas e de ideias hegemônicas; e 2) o turismo, é antes de tudo, um fenômeno social, complexo em si.

A partir da percepção dessas características, tem-se verificado atualmente uma série de novos debates e resignificações no que se entende por desenvolvimento no turismo, sobretudo porque essas discussões estão vinculadas às crises conceituais do que seja o desenvolvimento em um sentido mais amplo, entendendo como necessário o crescimento econômico, mas não se limitando a ele. Rompendo-se, portanto, com o tradicional juízo de que o desenvolvimento é um padrão mundial almejado, que significa industrialização, consumo e uso tecnológico.

Assim, a partir da década de 1970 inicia-se uma nova noção de desenvolvimento, que encaminharia as discussões para pensar um desenvolvimento que "tenha uma base social, econômica, cultural e ambiental mais sustentável” (ALMEIDA, 2001, p. 20). Neste sentido, as novas significações do desenvolvimento como uma forma de reprodução econômica e social mais equilibrada recebeu várias nomenclaturas. Passando pelo ecodesenvolvimento, desenvolvimento alternativo até desembocar em desenvolvimento sustentável. Esse último nome parece ter sido o mais bem aceito, talvez por ter sido usado nas principais publicações do período inicial das propagações sobre o assunto, como no relatório Brundtland, para o qual o desenvolvimento sustentável significa: "[...] aquele que atende as necessidades do presente sem comprometer a possibilidade de as gerações futuras atenderem a suas próprias necessidades" (CMMAD, 1988, p. 46).

As discussões sobre desenvolvimento sustentável encaminharam desdobramentos e novas significações ao desenvolvimento, a exemplo do desenvolvimento local, desenvolvimento humano e desenvolvimento como liberdade. Nesse contexto, o artigo tem como objetivo aprofundar a discussão da abordagem do 
desenvolvimento como liberdade do autor indiano Amartya Sen (1988, 1993, 2000, 2011), que ao longo de sua carreira tem feito contribuições relevantes à área. Para o autor, a liberdade é tema central na análise do desenvolvimento, pois é ao mesmo tempo um elemento constitutivo e instrumental (SEN, 2000).

No que tange ao turismo e a sua relação com o desenvolvimento, percebe-se que autores da área (RODRIGUES, 1999; BUARQUE, 2006, 2008; ZAPATA, ZAPATA, 2006; RUA, 2006; BENI, 2007; AGUIAR, 2007) têm seguido essas orientações mais amplas do significado do desenvolvimento, que ultrapassa os aspectos econômicos e, inclui dimensões vinculadas à melhoria da qualidade de vida das pessoas. No entanto, as publicações sobre o assunto não têm sido pontuais, abordando-se geralmente entendimentos generalistas e não articulando de forma sistemática à consubstanciação de uma discussão balizadora do que se entenda por desenvolvimento induzido pelo turismo.

Nessa perspectiva, como forma de contribuir para essas lacunas encontradas, objetivou-se nesse artigo empreender a discussão do binômio: desenvolvimento e turismo, realizando-se uma leitura ética do desenvolvimento pautado na atividade turística ${ }^{1}$. Para isso foi realizada a articulação do desenvolvimento entendido como expansão das capacidades e liberdades dos indivíduos - o desenvolvimento como liberdade - com o turismo, buscando mostrar de que forma o turismo pode, enquanto atividade econômica, contribuir para a transformação social. Para tal empreendimento, no primeiro momento, foram resgatados os principais elementos da abordagem do desenvolvimento como liberdade; e em seguida, esses direcionamentos foram relacionados com o turismo.

\section{A LEITURA ÉTICA DO DESENVOLVIMENTO COMO LIBERDADE}

A abordagem do desenvolvimento como liberdade deve ser entendida como uma leitura ética do desenvolvimento que tenta agregar diversos elementos imprescindíveis que devem ser levados em consideração na avaliação do desenvolvimento de uma

\footnotetext{
${ }^{1} \mathrm{O}$ artigo faz parte de uma pesquisa de mestrado que objetivou avaliar o Programa de Desenvolvimento do Turismo - PRODETUR, em um município do Rio Grande do Norte - Parnamirim. Para exame ver LIMA (2013).
} 
determinada sociedade. Essa leitura, conforme realizada por Amartya Sen (1988, 1993, 2000, 2011), rompe com a estreita relação do desenvolvimento em sua acepção geral com o crescimento (desenvolvimento) econômico.

De forma geral, na literatura econômica encontra-se um quadro, em que existem duas correntes, uma que encara desenvolvimento e crescimento como sinônimos, representada pela tradição clássica e neoclássica; e outra que conceitua desenvolvimento econômico para além do crescimento strictu senso, incluindo, pois, mudanças na qualidade de vida das pessoas. Mas mesmo os autores que percebem desenvolvimento econômico para além de crescimento econômico, estabelecem uma relação direta entre aumento da propriedade material - incrementos positivos no produto e na renda - e aumento de bem-estar da população, o que não é de forma alguma uma relação clara. Sen (1988, p. 15) aborda a respeito:

[...] no matter in which direction one argues, there is an issue here of great importance to the assessment of development that is completely obscured by the GNP information. Even if GNP did everything it is expected to do (and there are very strong reasons for doubting this possibility), even then the information provided by GNP must remain fundamentally inadequate for the concept of development. ${ }^{2}$

$\mathrm{O}$ autor argumenta no sentido de que o aumento do Produto Interno Bruto - PIB pode e deve influenciar na melhoria das condições de vida das pessoas, mas ai encontrase uma potencialidade apenas e não uma realização propriamente dita. Torna-se necessário, portanto, ao se falar em mensuração do desenvolvimento, não ter como parâmetros apenas os meios (produtos e renda), mas mensurar em que isso influencia nos fins, ou seja, na contribuição para amenizar de fato a pobreza, a miséria e melhorar níveis de bem-estar e satisfação das necessidades básicas.

O problema foi e está ainda no fato da análise econômica afastar-se das questões não direcionadas estritamente aos indicadores econômicos, ocasionando consequentemente a concepção e análise do desenvolvimento nesse viés. Contudo, a partir da década de 1970, o paradigma do desenvolvimento como um padrão mundial

\footnotetext{
${ }^{2}$ [...] não importa em que direção se argumenta, há um problema aqui de grande importância para a avaliação do desenvolvimento que é completamente obscurecida pela informação PIB. Mesmo se o PIB fez tudo o que é esperado para fazer (e há razões muito fortes para duvidar dessa possibilidade), mesmo assim a informação prestada pelo PIB deve permanecer fundamentalmente inadequada para o conceito de desenvolvimento (tradução nossa).
} 
começou a ser questionado em suas bases por pesquisadores, por duas razões principais: 1) o crescimento de forma não planejada e degradadora ao meio ambiente põe em risco a própria vida na Terra em longo prazo; 2) o desenvolvimento não pode ser tido como um padrão mundial; é necessário saber o tipo de desenvolvimento que se almeja alcançar para cada localidade, porque as realidades sociais são distintas e não existe um modelo único a ser seguido (FURTADO, 1974; ALMEIDA, 2001; NOBRE, 2002).

Amartya Sen (2000), ao discutir o desenvolvimento, coloca como direcionamento central a percepção de que os diferentes direitos, oportunidades e intitulamentos - entitlement - permitem a expansão geral da liberdade humana e consequentemente promovem o desenvolvimento. O autor afirma que (2000, p. 26): "[...] com oportunidades sociais adequadas, os indivíduos podem efetivamente moldar seu próprio destino e ajudar uns aos outros".

Os entitlements - significam na abordagem Senniana, o conjunto de pacotes de bens que uma pessoa possui - a dotação; bem como aqueles que podem ser adquiridos mediante canais legítimos de aquisição de que possa dispor ${ }^{3}$. Nessa perspectiva, os intitulamentos devem ser expandidos pelo desenvolvimento, já que isso aumenta a liberdade dos indivíduos.

Para o autor, diferentes tipos de liberdade se inter-relacionam, e um tipo de liberdade, contribui para expansão de liberdades de outros tipos, contribuindo assim para a liberdade global da pessoa. Desse modo, a criação de diversas oportunidades sociais, como são exemplos, à educação pública, a saúde de qualidade, uma imprensa livre e ativa, pode contribuir em maior ou menor grau para diminuir taxas de mortalidade, que por sua vez, reforçam a influência sobre a educação básica, que influenciam em comportamentos de taxas de fecundidade, e contribuem para o desenvolvimento.

As liberdades são distintas, mas inter-relacionadas, atuam complementando-se e todas juntas ajudam a promover a liberdade geral de uma pessoa. Nesse sentido, além de ser o "meio" (aspectos constitutivos do desenvolvimento), são também o principal fim do desenvolvimento, envolvendo a expansão das capacidades e da liberdade e consequentemente da melhoria da qualidade de vida dos indivíduos. Em função disso,

\footnotetext{
3 “"...] Uma pessoa passa fome quando seu entitlement não inclui, no conjunto [que é formado pelos pacotes alternativos de bens que ela pode adquirir], nenhum pacote de bens que contenha uma quantidade adequada de alimentos" (SEN, 2000, p. 54).
} 
na avaliação de desenvolvimento de uma dada sociedade, não se deve levar em consideração somente os avanços tecnológicos ou o crescimento do PIB, mas também verificar em que medida as capacidades e liberdades dos sujeitos sociais foram realmente expandidas (SEN, 1988, 1993, 2000).

Sen (2000) denomina de liberdades instrumentais as que considera elementares, que são aquelas como ser capaz de evitar a pobreza e o comprometimento da vida, bem como aquelas importantes socialmente como saber ler e fazer cálculos aritméticos, bem como possibilidades de participação política e liberdade de expressão (SEN, 2000). O desenvolvimento deve, pois, envolver a expansão dessas. As liberdades instrumentais ${ }^{4}$ são cinco, conforme o quadro a seguir mostra:

QUADRO 1 - LIBERDADES INSTRUMENTAIS

\begin{tabular}{|c|c|}
\hline LIBERDADES & SIGNIFICAÇÃO \\
\hline Liberdades Políticas & $\begin{array}{l}\text { São os direitos abrangentes em que é possível dispor em uma } \\
\text { democracia, como liberdade de expressão política, possibilidade de } \\
\text { escolher, fiscalizar e criticar governantes, diálogos públicos, entre } \\
\text { outros. }\end{array}$ \\
\hline Facilidades Econômicas & $\begin{array}{l}\text { São as possibilidades dos indivíduos de uma sociedade de utilizar } \\
\text { recursos econômicos para propósitos de consumo, troca e /ou } \\
\text { produção. }\end{array}$ \\
\hline Oportunidades Sociais & $\begin{array}{l}\text { São aquelas disposições sociais disponíveis em uma dada sociedade } \\
\text { como educação e saúde; as quais influenciam a liberdade } \\
\text { substantiva de o indivíduo viver melhor. Essas facilidades são } \\
\text { importantes não só para a condução da vida privada, mas também } \\
\text { para uma participação mais ativa em atividades econômicas e } \\
\text { políticas. }\end{array}$ \\
\hline Garantias de Transparências & $\begin{array}{l}\text { São referentes à transparência de dados e notícias que permitam } \\
\text { entre outras coisas, inibir atos de corrupção e transações ilícitas. }\end{array}$ \\
\hline Segurança Protetora & $\begin{array}{l}\text { Refere-se à rede de segurança social que objetiva evitar que pessoas } \\
\text { de uma dada sociedade venham a morrer pela sua falta, como } \\
\text { benefícios aos desempregados, distribuição de alimentos em crises } \\
\text { de fome coletiva, entre outras. }\end{array}$ \\
\hline
\end{tabular}

Fonte: Sen (2000).

O autor atenta para diversas fontes de privações da liberdade: pobreza, tirania, carência de oportunidades econômicas, destituição social sistemática, negligência dos serviços públicos, intolerância ou interferência excessiva de Estados repressivos. Para que ocorra o desenvolvimento é necessário remover estas diversas fontes de privações. Neste sentido, a liberdade seria central para o processo de desenvolvimento por duas razões: (1) razão avaliatória: a avaliação de progresso tem de ser feita verificando-se se

\footnotetext{
${ }^{4}$ É importante ressaltar que não há uma ordem de importância entre as liberdades instrumentais, todas são importantes e atuam complementando-se e influenciando-se mutuamente.
} 
houve aumento das liberdades das pessoas; (2) a razão da eficácia: a realização do desenvolvimento depende inteiramente da condição de agente das pessoas (SEN, 2000).

A condição de agente é central para Sen, que significa um indivíduo membro do público e como participante de ações econômicas, sociais e políticas. Alguém que age e ocasiona mudança (SEN, 2000, 2011). Evidencia-se, pois, que a avaliação do desenvolvimento deve ter uma ênfase nas vidas humanas, e nas capacidades que são expandidas. Nessa abordagem, as pessoas não são beneficiárias passivas das disposições disponíveis, ao contrário, são agentes ativos da mudança e devem traçar seu próprio caminho.

Na consideração da abordagem do desenvolvimento como liberdade, observa-se a relação entre dois conceitos centrais para Sen, que são "capacidades e liberdades". Sempre são trabalhados conjuntamente, pois as capacidades são aspectos da liberdade. As capacidades são as reais possibilidades de uma pessoa para promover quaisquer objetivos que tenha razão para realizar, podendo estar ligados ou não ao bem-estar pessoal, ou seja, é sua liberdade para ter estilos de vida diversos, que julgue importantes. Esses estilos de vida (as capacidades) derivam das combinações alternativas de funcionamentos cuja realização é possível (SEN, 2000).

O conceito de funcionamentos tem raízes aristotélicas e reflete as várias coisas que uma pessoa considera valioso fazer ou ter ${ }^{5}$. Já as capacidades elucubram a possibilidade efetiva de realizar os funcionamentos (SEN, 2000). Uma pessoa, por exemplo, pode considerar muito valioso participar da vida política, mas se vive em um país de regime autoritário, não poderá fazê-lo, o que é uma privação de sua capacidade e que compromete um aspecto da liberdade dessa pessoa.

A liberdade é importante principalmente por duas razões diferentes. Primeiro, ela possibilita mais oportunidade de buscar as diferentes coisas que as pessoas valorizam; em segundo o próprio processo de escolha é relevante. Isso significa que o principal não é exatamente o que se escolhe e o tipo de vida que se leva, mas as opções disponíveis para eleger como viver e o tipo de vida que se pode levar. Essa liberdade de escolha contribui significativamente para o bem-estar dos indivíduos (SEN, 2000, 2011).

\footnotetext{
${ }^{5}$ Para Sen (2000, p. 95): “[...] os funcionamentos valorizados podem variar dos elementos, como ser adequadamente nutrido e livre de doenças evitáveis, a atividades ou estados pessoais muito complexos, como poder participar da vida da comunidade e ter respeito próprio".
} 
Ao avaliarmos nossas vidas, temos razões para estarmos interessados não apenas no tipo de vida que conseguimos levar, mas também na liberdade que realmente temos para escolher entre diferentes estilos e modos de vida. $\mathrm{Na}$ verdade, a liberdade para determinar a natureza de nossas vidas é um dos aspectos valiosos da experiência de viver que temos razão para estimar [...] (SEN, 2011, p. 261).

Neste viés de análise percebe-se que o melhoramento dos "objetos inanimados" (SEN, 1988, 1993, 2000, 2011) como o Produto Interno Bruto - PIB, PNB e a industrialização são insuficientes na análise do desenvolvimento, apesar da importância como meios para alcançar os fins desejados, isto é, o impacto que possuem nas vidas e liberdades das pessoas envolvidas. Tem-se de valorizá-los então condicionalmente pelo que ajudam as pessoas a realizar.

Assim, para Sen (2000, p. 23): “as políticas públicas visam ao aumento das capacidades humanas e das liberdades substantivas em geral e podem funcionar por meio da promoção dessas liberdades". Essas capacidades e liberdades são expandidas por meio das "efetivações", que são as "conquistas" de uma pessoa. Portanto, ao se estudar uma política específica, deve-se sempre considerar em que medida a política gerou o alcance de conquistas (efetivações) na vida do público-alvo.

Consoante a isso, fica evidente que a comparação entre as vantagens que diferentes pessoas possuem, tem de se centrar em seu conjunto capacitário, isto é, quais são as capacidades totais que conseguem desfrutar, pois estas demonstram o poder para fazer o que desejam, evidencia em última instância o poder de agente de que gozam. Não esquecendo que as diversas capacidades individuais dependem crucialmente das disposições econômicas, sociais e políticas presentes no meio em que vivem.

Observando os diversos conceitos das abordagens do desenvolvimento em uma escala mais local, referente aos sujeitos, se pode perceber através das reflexões de Sen (1988, 1993, 2000, 2011), que ele complexifica e ajuda de forma mais substancial a entender essas novas perspectivas do desenvolvimento. Diante deste cenário, serão relacionados na próxima sessão, os princípios do desenvolvimento como liberdade, com o turismo, verificando de que forma a atividade turística pode se transformar em uma prática de expansão das capacidades e liberdade dos indivíduos residentes em uma localidade. 


\section{O DESENVOLVIMENTO COMO LIBERDADE NO TURISMO: PRINCÍPIOS PARA A EXPANSÃO DA LIBERDADE EM ÂMBITO LOCAL}

Nessa sessão tem-se o objetivo de mostrar de que forma o turismo, visto geralmente em suas abordagens econômicas e vinculadas à lógica de acumulação do sistema capitalista, pode incentivar o desenvolvimento, com relação à transformação social e não apenas como mola propulsora para o crescimento econômico.

O turismo pode incentivar a melhoria da qualidade de vida das pessoas residentes nos destinos turísticos, desde que todos os atores locais estejam em sintonia e dispostos a cooperar mutuamente em busca do desenvolvimento. Desse modo, a gestão pública, a iniciativa privada, a sociedade civil e a população local, possuem papéis específicos no processo de mudança social. Dessa forma, mostra-se aqui de que forma à atividade turística pode impulsionar a expansão das liberdades instrumentais conforme colocadas por Sen (2000): (1) liberdades políticas, (2) facilidades econômicas, (3) oportunidades sociais, (4) garantias de transparência e (5) segurança protetora. No primeiro momento, através do papel das políticas públicas de turismo, na definição de ações, e em um segundo momento, pela mobilização dos próprios atores, criando parcerias e intervenções que ocasionem melhorias sociais.

A primeira liberdade que se põe a discutir refere-se à - liberdades políticas - que são importantes porque possibilitam aos cidadãos de um determinado lugar gozar de todos os direitos correspondentes às democracias em sentido abrangente, como escolher quem deve governar, poder fiscalizar e criticar os representantes políticos, ter expressão política, imprensa sem censura, oportunidades de diálogo público, dissensão e crítica, direito a voto, participação coletiva, entre outros aspectos (SEN, 2000).

O turismo pode incentivar de diferentes maneiras a expansão das liberdades políticas, como no caso da população de um determinado destino, participar do processo da tomada de decisões a respeito dos rumos que a atividade turística está tendo na localidade; também no momento em que se organiza em associações/cooperativas, tanto no sentido de fiscalizar as ações que o poder público está tomando com relação ao turismo, quanto no sentido de participar da cadeia produtiva do turismo, na oferta de produtos turísticos locais. Em todas essas ações o que está sendo incentivado é a condição de agente dos indivíduos. 
Assim sendo, salienta-se o papel imprescindível que as pessoas possuem no processo de desenvolvimento. O que os indivíduos pensam e o que fazem impacta diretamente o meio social em que vivem. Sujeitos ativos conseguem de forma mais efetiva contribuir para a transformação social (GREEN, 2009). É exatamente a ideia de protagonismo, de não passividade, que esta imbuída no conceito Senniano de agente.

Poder-se-ia então perguntar por que em vários lugares do planeta, a maior parte das pessoas, em situações de privação, permanecem estáticas, sem lutar conjuntamente por maior respeito e menos desigualdades sociais. A resposta para esse questionamento parece estar nas privações diárias que esses diversos indivíduos sofrem (DOWBOR, 2010). A necessidade pelo pouco de cada dia para sobreviver, é tão mais urgente, que não sobra espaço para a participação na vida pública em sociedade. Além disso, a falta de uma cultura participativa oculta o poder imbuído nas organizações sociais, por isso, as pessoas não percebem o quanto poderiam alcançar se reivindicassem organizadamente (ZAPATA, ZAPATA, 2006; DOWBOR, 2010).

Dowbor (2010) afirma que os pobres vivem precariamente não por falta de criatividade ou vontade, mas por falta de articulação nos sistemas de apoio. Isto é, primeiro deveriam existir mecanismos de incentivos públicos para a superação de necessidades básicas, depois para incitar as pessoas a participar do crescimento.

Ressalte-se que quando se fala em participação se está fazendo referência a Estados democráticos, pois nos países autoritários, a falta de liberdade política é mais um dos fatores que tolhem a condição de agente dos indivíduos. Mas levando em consideração que se pertença ao território brasileiro, no qual se goza dos direitos democráticos, se faz indispensável, portanto, mostrar que o processo participativo e o debate público são fatores condicionais para o desenvolvimento, especialmente, no turismo, fenômeno complexo e que envolve todos os segmentos sociais, direta e/ou indiretamente.

Buarque (2006) corrobora com essa ideia, ao afirmar que o turismo é um dos poucos setores mundiais, que para crescer precisa incluir os excluídos socialmente. Essa característica o diferencia da indústria comum, que para expandir os lucros, pode simplesmente aumentar o consumo dentro de determinado grupo, sem precisar ampliarse para outros, além de que, consegue cada vez mais produzir com menos homens e mais máquinas. O turismo enquanto atividade do setor de serviços é distinto, porque 
precisa abarcar cada vez maior quantidade de pessoas para continuar crescendo e manter-se; e sua mão de obra é composta de diferentes níveis de especialização, do mensageiro de hotel ao administrador hoteleiro.

Rua (2006) contribui com essa concepção ao argumentar que o turismo pode contribuir para a inclusão social, principalmente por três fatores: em primeiro lugar, o turismo é uma atividade que possibilita o intercâmbio entre diferentes culturas, fato que pode contribuir para estimular o respeito e a preservação por diferentes comunidades. Em segundo lugar, essas relações são geralmente prazerosas o que permite o estabelecimento de empatia entre diferentes atores. Terceiro, propicia oportunidades de geração de trabalho e renda.

Um autor que colabora nessa discussão é Castoriadis ${ }^{6}$ apud Souza $(1994,1996)$, que define a autonomia como princípio balizador do desenvolvimento. Nesse entendimento, as pessoas de determinado espaço territorial, cada povo, deve assumir a função de dar significado à palavra desenvolvimento; pautando-se em suas necessidades e peculiaridades regionais, conforme sua cultura. Esse processo, não se furta ao estabelecimento de metas a serem cumpridas, entretanto, a escolha dos objetivos principais a serem alcançados deve ser por via democrática, de luta e negociação entre visões diferentes.

Outro autor que ressalta a necessidade de protagonismo das pessoas no processo de desenvolvimento e na transformação social é Green (2009), que utiliza o termo cidadania ativa, para descrever a condição em que as pessoas exercitam os seus direitos civis e políticos, em busca de melhorias na vida econômica e social. O que acontece muitas vezes por meio de ações coletivas em prol de benefícios comuns.

O estímulo por parte do poder público para desenvolver nas pessoas o espírito participativo, pode ser um aspecto importante para desenvolver a autonomia, das diversas formas que pode ocorrer. Sen (2011) aborda que a expansão da educação básica e escolaridade, aumento da independência econômica, e outras alterações sociais e econômicas ajudam os indivíduos a serem cidadãos ativos. Poder-se-ia destacar, então,

\footnotetext{
${ }^{6}$ Algumas das obras citadas de Castoriadis por Souza $(1994,1996)$ foram: Introdução: socialismo e sociedade autônoma. In: Socialismo ou barbárie. O conteúdo do socialismo. São Paulo: Brasiliense, 1983 ; La polis grecque et la création de la démocratie. In: Domaines de /'homme. Les carrefours du labyrinthe 11. Paris: Seuil, 1986 ; La logique des magmas el la question de I'aulonomie. In: Domaines de /'homme. Les carrefours du labyrinthe 11. Paris: Seuil, 1986 ; Pouvoir, polilique, autonomie. In: Le monde moreelé. Les carrefours du labyrinthe 111. Paris: Seuil, 1990.
} 
o papel central que possui o Estado no incentivo à emergência de indivíduos ativos participantes de ações para o desenvolvimento como liberdade.

No Estado brasileiro, a constituição de 1988 impôs a descentralização como mote administrativo, o que possibilitou maior autonomia aos Estados e municípios (DOWBOR, 2010). A partir desse momento, os municípios transformaram-se nas bases territoriais, onde o planejamento das ações passou a ser concretizado, aumentando suas responsabilidades governamentais e de gestão de recursos financeiros, constituindo-se conforme afirma Dowbor (2010, p. 106): “[...] o bloco básico de construção do conjunto".

Esse novo formato dos entes federativos possibilitou a resignificação do poder local. Para Costa (1996, p. 113) o poder local no Brasil contemporâneo passou a ser "[...] portador de possibilidades de gerenciamento eficiente dos recursos públicos e protagonista de iniciativas de desenvolvimento da vida econômica e social".

Percebe-se, portanto, um deslocamento no papel assumido. Antes desse período o poder local não possuía autonomia, sendo apenas um agente implementador de decisões tomadas no nível federal. Após a promulgação da constituição de 1988, o poder local assumiu o papel de protagonista, agente e canalizador de sinergias no engajamento de iniciativas econômicas, políticas e sociais no âmbito local (COSTA, 1996).

Por sua vez, a autonomia dada aos municípios brasileiros para a gestão de políticas públicas, seja de iniciativas próprias ou da adesão a políticas nacionais, e o princípio constitucional da participação social como elemento fundamental na formulação e controle das políticas em todos os níveis, ocasionou a criação de canais públicos populares, como os conselhos gestores, que são “[...] canais de participação que estimulam representantes da população e membros do poder púbico estadual em práticas que dizem respeito à gestão dos bens públicos" (GOHN, 2001, p. 7). Sendo, portanto, um novo ente que possibilita o controle social, a gestão e a deliberação, na responsabilidade dividida de papéis, entre poder público e a coletividade.

Pode-se ainda acrescentar, os novos papéis assumidos pela sociedade civil nesse momento de reforma do Estado. Bresser Pereira (1999) observa que a expansão da sociedade civil objetivou fortalecer o Estado e não reduzi-lo ao mínimo. O autor inclusive argumenta que a sociedade civil, situada entre Estado e mercado, não é 
dominada por nenhum dos dois, deixando de ser passiva, buscando ativamente contribuir para reformá-los. Para o autor, um Estado forte, com capacidade de controle social, exige uma sociedade civil forte, comparada a mesma capacidade de controle social.

A sociedade civil organizada, englobando o associativismo de tipo economia solidária e as Organizações Não Governamentais, são formas inovadoras e legítimas de influenciar associações sociais, que incentivem uma cultura cívica e uma maior autonomia na luta pelos direitos sociais. Com relação a isso, Sen (2000, p. 46) pontua que os usos que os sujeitos dão às liberdades dependem em grande medida “[...] de associações sociais - particularmente da formação interativa de percepções do público e da compreensão cooperativa de problemas e soluções".

No âmbito do turismo, várias iniciativas vêm sendo criadas, como: as redes de comércio justo; o turismo pró-pobre; o turismo responsável; o fomento de práticas de economia solidária, entre outras. De todas as iniciativas, o turismo de base comunitária (TBC) é aquele que possui maior destaque. Constitui-se em um processo no qual a comunidade receptiva está envolvida desde a formulação até a implementação das atividades ligadas ao turismo, isto é, ela tem de certo modo o controle da atividade. Sendo matéria prima do TBC "os saberes e fazeres da comunidade", trazendo benefícios sociais, econômicos e culturais para todos os membros, o que ocasiona uma melhora da qualidade de vida da população (INSTITUTO ECOBRASIL, s./d.).

Putnan (1996) já tinha apontado através de uma pesquisa empírica que durou vinte anos na Itália moderna, a forte relação existente entre comunidade cívica e o desempenho eficaz das instituições públicas. Isto é, quanto mais cívica é uma região, melhor será seu desempenho institucional, isso porque o contexto moldaria o desempenho prático das instituições públicas. Para o autor, comunidade cívica se constitui em participação cívica, igualdade política, solidariedade, confiança, tolerância e associações, que são traduções do capital social presente no contexto social.

No capital social se leva em conta a confiança, as normas e cadeias de relações sociais como elementos centrais. Sendo a confiança o componente principal, quanto mais houver em uma comunidade possibilidades de afiliação de seus cidadãos através de associações baseadas na confiança mútua, maior é o volume de capital social presente na mesma (PUTNAN, 1996). 
Para Zapata e Zapata (2006) o turismo seria uma atividade muito mais promissora e socialmente inclusiva se desenvolvesse o capital social nas sociedades onde se faz presente. Contudo, os autores observam que no Brasil de forma geral houve uma incipiência na geração de capital social, em parte relacionado ao passado recente autoritário, o que não despertou nas pessoas o afloramento dos aspectos de confiança, solidariedade e associação. No turismo em particular, a geração de capital social segue esse cenário global, mas também é influenciado por outros fatores, entre os quais, podese citar a falta de articulação: entre as empresas da cadeia produtiva do turismo; entre os pertencentes às comunidades próximas aos atrativos turísticos e com relação à gestão pública.

Os autores ressaltam que há inúmeras formas de aumentar o capital social no turismo. Podendo-se citar: a construção de um ambiente social de confiança e de colaboração entre os agentes; o favorecimento de parcerias entre atores considerados de grande porte com aqueles considerados de menor porte, desde que essa relação possibilite complementaridade e o estímulo à participação das comunidades locais no processo (ZAPATA; ZAPATA, 2006).

A partir dessas considerações, se pode afirmar que a organização social, das diversas formas possíveis e a consequente geração de capital social, tendo como eixo articulador, a condição de agente das pessoas, é elemento constitutivo e instrumental do desenvolvimento, tendo papel estratégico no turismo na expansão das capacidades e liberdade das pessoas.

Outra liberdade instrumental abordada por Sen (2000) refere-se à - Facilidades Econômicas - que são as oportunidades que os indivíduos têm para utilizar recursos econômicos no mercado, para consumo, produção e ou troca. Quanto maiores forem os recursos disponíveis de uma pessoa, maiores serão seus intitulamentos, ou seja, maior é o pacote de bens a que ela tem acesso. Para o autor, na medida em que a riqueza de um país aumenta, isso se reflete no aumento dos intitulamentos da população.

Pode-se afirmar que, o turismo é uma das atividades econômicas mais significativas no contexto contemporâneo, possibilitando contribuir relevantemente para a expansão das facilidades econômicas da população. Neste sentido, tem-se como dizer que a crítica ao desenvolvimento baseado unicamente no economicismo deve ser dissociada da crítica à economia. Isso porque como já percebido, realmente não se pode 
falar de desenvolvimento apenas baseando-se nos indicadores econômicos, mas também não se pode falar de desenvolvimento sem o crescimento da economia. Nas diversas regiões, especialmente nas mais carentes, deve-se buscar atingir o crescimento da renda local “[...] por meio de atividades econômicas viáveis e competitivas [...] apenas com economia suficiente e competitiva gerando riqueza local sustentável pode-se falar, efetivamente em desenvolvimento [...]" (BUARQUE, 2008, p. 26).

Tudo depende de como os benefícios do crescimento econômico são aproveitados em prol da diminuição das desigualdades regionais, ou seja, de como o uso dos mercados ocorre combinado com a expansão de oportunidades sociais. Sen (2011, p. 381) observa que:

[...] devemos considerar, por exemplo, a pobreza econômica. Portanto, temos razão para nos interessar pelo crescimento econômico, mesmo nos termos bastante limitados do crescimento do PNB ou do PIB per capita, já que o aumento da renda real pode abrir caminho para algumas realizações muito importantes; por exemplo, a conexão geral entre crescimento econômico tende a expandir o tamanho da receita pública, que pode ser usada para fins sociais, como escolas, assistência médica e à saúde e outros serviços que melhoram diretamente a vida e as capacidades das pessoas.

Os gestores públicos podem realizar uma redistribuição mais equitativa da receita pública gerada pelo crescimento econômico, através de várias ações sociais. Buarque (2008, p. 28) comenta que no Brasil, e especificamente no Nordeste, as iniciativas de desenvolvimento tendem a olhar com desconfiança para a base da economia, e, sobretudo, para os órgãos públicos locais, numa desproporcional crítica ao economicismo. Fato que reduz as efetivas possibilidades de desenvolvimento. Para mudar esse quadro, é necessário agregar valor à cadeia produtiva local com a finalidade de aumentar a competitividade, buscando gerar riqueza e trabalho, e assim a capacidade de investimento na e da localidade. Sendo imprescindível não depender unicamente de fundos e programas estaduais e/ou municipais.

A busca da competitividade referida pelo autor, diz respeito a explorar as condições e potencialidades dos municípios, suas bases mercadológicas endógenas, com o objetivo de alcançar vantagens locacionais com base no que se tem e no que se pode constituir. Devem-se procurar espaços de competitividade com critério e seletividade, escolhendo-se aquelas áreas em que se possua diferencial. 
A base da economia gerada pelo turismo vem dos ativos endógenos, naturais, sociais, culturais e históricos de cada localidade. Esse fato é positivo, tendo em vista que permite criar externalidades no espaço econômico, com a finalidade de atrair investimento produtivo que permitirá uma maior integração na economia regional e/ou nacional. Essas externalidades e suas potencialidades: infraestrutura econômica, recursos humanos (população educada e preparada profissionalmente), desenvolvimento tecnológico, entre outros, são principalmente incentivados e organizados pelo poder público (BUARQUE, 2008).

A essas considerações postas, se acrescenta a necessidade de articulação do local ao global. Essa integração é facilitada pelos avanços tecnológicos e informacionais. Em função disso, as empresas consideradas de pequeno porte podem se tornar mais competitivas, porque possuem nesse novo momento, possibilidades de flexibilidade no processo de produção e distribuição. Como exemplo, pode-se citar a associação de produtores localizados em diferentes espaços regionais; processo muito mais visível agora do que em décadas anteriores (BUARQUE, 2008).

Assim, entende-se que, com as diversas oportunidades disponíveis no mundo informacional, as empresas de pequeno porte inseridas na cadeia do turismo podem organizar formas de gestão e oferecer produtos turísticos de forma mais competitiva (BUARQUE, 2008). Contudo, não se pode esquecer que é muito importante o estabelecimento de parcerias entre atores considerados de grande porte com aqueles considerados de menor porte, desde que essa relação possibilite complementaridade, conforme ressaltam Zapata e Zapata (2006).

Some-se a isso, o fato de que as próprias empresas turísticas podem assumir responsabilidades e trabalhar em prol das localidades onde estejam localizadas. Buarque (2006) cita como exemplo, os casos de hotéis que criam Organizações Não Governamentais (ONGs) para trabalhar em aspectos deficitários de comunidades, como no apoio as crianças da região em que estão instalados para que terminem seus estudos. As empresas participantes dessas redes de solidariedades acabam conquistando a simpatia dos autóctones residentes em seu entorno.

Tratar-se-á agora de outra liberdade instrumental abordada por Sen (2000) que corresponde à - Oportunidades Sociais - essas se referem às disposições presentes na sociedade que possibilitam ao indivíduo viver melhor, como a oferta de uma educação 
pública de qualidade, um sistema de saúde eficiente; bem como outras ações que possibilitem as pessoas à possibilidade de participar da vida social, econômica e política, dando-os maior autonomia na condução de sua vida individual, bem como na participação de ações coletivas.

Através da atividade turística é possível propiciar uma série de oportunidades sociais, como geração de postos de trabalhos nas atividades ligadas aos setores de hospedagem, alimentação, agenciamento, locação, entretenimento e lazer. Além de que, políticas de turismo podem incentivar em diversos aspectos melhorias sociais, como é o caso do PRODETUR/NE ${ }^{7}$ que possui ações de incentivo a expansão de serviços públicos de infraestrutura urbana, como água tratada, saneamento básico e coleta de lixo. Bem como oferta de cursos de qualificação profissional e realização de obras de recuperação no meio ambiente (LIMA, 2013).

Isso acontece porque no Brasil, o acesso aos serviços básicos de infraestrutura urbana não cobrem todas as regiões brasileiras, ficando uma parte considerável descoberta, serviços esses que são básicos para a saúde da população, como é o caso da água tratada, saneamento básico e coleta de lixo (LIMA, 2013). Pelo fato das políticas urbanas não darem conta da demanda por esses serviços, programas como o PRODETUR/NE, desde sua concepção vêm realizando a expansão desses equipamentos urbanos.

Com relação à oferta dos cursos de qualificação profissional, se pode afirmar o quanto isso é necessário para aqueles sujeitos que não possuíram oportunidades escolares adequadas, ficando muitas vezes excluídos do mercado de trabalho, pela falta da qualificação mínima exigida. Nesta perspectiva, ao se qualificarem, aumentam as chances de concorrerem às vagas no mercado de trabalho, cada vez mais competitivo. Algo fundamental para disporem de um mínimo de renda para participarem economicamente dos mercados, isto é, para aumentarem seus intitulamentos (LIMA, 2013).

Já com relação às obras de recuperação ambiental, deve-se citar como exemplo o PRODETUR/NE, que também atua nesse componente (LIMA, 2013). Com relação a isso, resolveu-se discorrer mais a respeito, tendo em vista, o significado do meio ambiente enquanto valor social e sua relevância para a qualidade de vida das pessoas. $\mathrm{O}$

\footnotetext{
${ }^{7}$ Programa de Desenvolvimento do Turismo - programa de crédito para o setor público, estados e municípios (BNB, 2005).
} 
meio ambiente está entre os chamados por Sen $(2000,2011)$ de bens públicos, que são aqueles em que as pessoas não consomem separadamente, mas conjuntamente. Portanto, não há como, ou não deveria existir como, um determinado grupo social privatizar áreas de preservação ambiental e/ou algum outro serviço ou bem de caráter público. Mesmo sabendo dessa assertiva, percebe-se que no Brasil, esse direito tem sido violado e algumas áreas públicas têm sido privatizadas, mesmo que de forma indireta.

Se for falado da atividade turística, esse fato fica evidente quando se observam as áreas costeiras nordestinas. $\mathrm{O}$ processo de valorização desses espaços nas últimas três décadas propiciou a instalação de redes hoteleiras internacionais. Fato que gerou, em alguns casos, a privatização de orlas inteiras. Em Natal, capital do Estado do Rio Grande do Norte, é possível constatar o fato ao se verificar a disposição dos hotéis ao longo da chamada Via Costeira Natalense; o que impossibilitou o uso daquela área pela população local (LIMA, 2013).

Para Sen (2011) quem compromete os usos conjuntos dos bens públicos, deve passar por restrições de comportamento. Contudo, para o autor, mais interessante seria a disseminação de valores e responsabilidades sociais - neste caso, da ética ambiental que diminuísse a imposição da autoridade estatal. No turismo, o indicado é não permitir que algum ator da cadeia produtiva se instale em espaços que devem ter seus usos assegurados coletivamente, como também deve ser garantido o respeito aos limites de uso do meio ambiente.

Não obstante, positivas são ações de valorização do meio ambiente em prol da atividade turística. O PRODETUR/NE possui entre suas obras, aquelas que objetivam fazer melhorias ambientais. Essas estão ligadas tanto a instalações de áreas de proteção ambiental quanto à recuperação de áreas degradadas. Essas obras não beneficiam somente a vinda de turistas, já que a condição paisagística é elemento de atração; mas, beneficiam também a população local, que contará com recursos naturais em melhores condições (LIMA, 2013).

Sen (2011) argumenta que o valor do meio ambiente não pode ser dissociado da vida das pessoas, não denotando apenas o que existe, mas quais perspectivas podem oferecer. Não se deve ter como foco apenas a preservação passiva, mas também a criação ativa. Ao mesmo tempo em que os seres humanos destroem o meio ambiente, 
também podem através da intervenção criativa, contribuir para enriquecê-lo e melhorálo:

[...] Ao pensarmos nos passos que podem ser dados para conter a destruição ambiental, temos de incluir a intervenção humana construtiva. Nosso poder de intervir com eficácia e raciocínio pode ser substancialmente reforçado pelo próprio processo de desenvolvimento [...] conceber o desenvolvimento com relação ao aumento da liberdade efetiva dos seres humanos promove a agência construtiva de pessoas comprometidas com atividades benéficas para o meio ambiente, diretamente dentro do domínio das realizações do desenvolvimento (SEN, 2011, p. 283).

O desenvolvimento propicia o enriquecimento do meio ambiente, já que este inclui as invenções humanas, que pode ser reforçado pelos agentes ativos. Neste contexto, Sen (2011) argumenta que o conceito de desenvolvimento sustentável deveria passar por uma reformatação, que inseriria além da satisfação das necessidades das pessoas, a ampliação das liberdades e capacidades dos indivíduos. Assim sendo, a atual geração não deveria intervir negativamente nas possibilidades das futuras gerações de também utilizar o meio ambiente e expandir suas liberdades e capacidades.

Continuando com as análises, a outra liberdade instrumental colocada por Sen (2000) refere-se à - Garantias de Transparência - que dizem respeito à garantia de acesso às informações de ações/instituições públicas, sempre que um cidadão assim o solicitar. Isso inclui o direito a revelação de informações relacionadas a órgãos públicos. Para o autor, essa liberdade instrumental é inibidora da corrupção, da irresponsabilidade financeira e de transações ilícitas.

O turismo influencia as garantias de transparência, sempre que em uma cidade/destino/localidade qualquer cidadão tiver acesso a quaisquer informações solicitadas a respeito da atividade turística, como fluxo turístico, receita gerada, investimentos realizados, entre outras. Notório observar quanto a isso, o fato das próprias políticas de turismo incentivarem essa liberdade instrumental, a exemplo do PRODETUR/NE, que possui como elemento integrante de acompanhamento, os conselhos gestores, que já são por si só, canais para discussão pública das intervenções realizadas no âmbito local (LIMA, 2013). Além de dispor de sistema online, onde é 
possibilitado a qualquer cidadão verificar o andamento dos projetos financiados pelo programa. $^{8}$

Por fim, a última liberdade instrumental referida por Sen (2000) refere-se à Segurança Protetora - rede responsável por proporcionar segurança social a toda população. Pode ser considerada rede de segurança protetora, os benefícios aos desempregados, renda periódica para indigentes, distribuição de alimentos em crises de fome coletiva e empregos públicos de emergência para os mais necessitados.

O turismo pode influenciar o fortalecimento da segurança protetora de determinada localidade, através do incremento que pode possibilitar à economia, que por sua vez, poderá ser investido na rede de segurança social. Nesse sentido, o turismo influencia a segurança protetora de forma indireta, através dos incrementos econômicos que pode gerar.

Por fim, se faz referência àquela que pode e deve ser a articuladora da potencial contribuição do turismo ao desenvolvimento, que é a gestão pública. O papel dos agentes desta é o de ser o criador, articulador e impulsionador de ações em prol da coletividade. Assim sendo, estando em um espaço democrático, aspectos como diálogo, interação pública e participação política contribuem para que os projetos sociais não sejam postos de forma autoritária junto a uma coletividade, e sim para que exista um amplo diálogo das prioridades sociais. Neste caso, se houver um uso efetivo das oportunidades de participação disponíveis, é possível estabelecer de forma compartilhada quais são as prioridades do desenvolvimento para determinado local (LIMA, 2013).

Sen (2011) discorre que há uma estreita relação entre a democracia e o desenvolvimento, pois as liberdades políticas e os direitos democráticos estão entre os componentes constitutivos do desenvolvimento. "A liberdade democrática pode certamente ser usada para promover a justiça social e favorecer uma política melhor e mais justa" (p. 386). Contudo, a democracia vai influenciar o desenvolvimento, dependendo dos usos que são dados às participações e articulações sociais (SEN, 2000, 2011). É particularmente significativo à participação dos cidadãos em torno de um projeto social.

\footnotetext{
${ }^{8}$ No site do banco do Nordeste está disponível o Centro de Informações ao Público - CIP: www.bnb.gov.br, do PRODETUR.
}

Turismo \& Sociedade (ISSN: 1983-5442). Curitiba, v. 7, n. 2, p. 201-227, abril de 2014. 
Buarque (2008) argumenta que a importância do Estado como agente regulador do planejamento no desenvolvimento, inclui a orientação da sociedade para um desenvolvimento sustentável que esteja assentado no tripé - conservação ambiental, crescimento econômico e equidade social. Neste mesmo sentido, Dowbor (2010) destaca a necessidade de um Estado forte, o que não significa que seja autoritário e demasiadamente burocrático, mas sim que tenha agilidade e transparência. É preciso que preste conta aos cidadãos e que utilize uma política articulada e descentralizada, na qual os problemas e ações serão discutidos com as sociedades locais.

Direcionamento parecido é posto por Green (2009) ao afirmar que nenhum país prosperou ao ter Estados fracos ou omissos, pois é papel do Estado, administrar ativamente o processo de desenvolvimento. O autor utiliza o termo - Estados efetivos para se referir a Estados capazes de garantir a segurança de seus cidadãos e o estado de direito, implementando uma estratégia para assegurar um crescimento econômico inclusivo, sendo essencialmente, indutor do desenvolvimento.

No caso do turismo, a gestão pública possui papel estratégico, em seus níveis inter e intrarregional, principalmente, na criação de infraestrutura básica e turística Essa base física é criada com a finalidade de atrair investimento privado, sendo característica do setor turístico, a parceria público/privado. No Brasil, as políticas públicas de turismo têm sido criadas, sobretudo, com esta finalidade (CRUZ, 2000; FONSECA, 2005).

Rua (2006) observa que, as políticas de turismo possuem o papel de eixo articulador de diversas políticas sociais. Isso porque o turismo pode tanto robustecer a infraestrutura material, com a urbanização e fortalecimento institucional; quanto pode ser uma política de educação, na qualificação de pessoas.

Neste sentido, destaca-se que é viável para a atividade turística, um meio ambiente conservado, uma cidade segura, uma população educada, pois se algo estiver em desacordo, pode gerar redução no número de turistas:

\footnotetext{
Um país sem educação, sem água e esgoto de qualidade, sem segurança, pode continuar, sem maiores dificuldades, sua industrialização voltada para os ricos. Mas ele terá um país que espanta turistas. Essa é a chance do setor turístico fazer crescer um movimento para a defesa de políticas de inclusão (BUARQUE, 2006, p. 82).
}

Percebe-se então que o setor turístico possui uma potencialidade em contribuir com políticas que beneficiem as populações dos destinos turísticos. Mas para que tal 
potencial se realize é indispensável uma gestão pública eficiente, articuladora de ações.

A figura a seguir demonstra de forma sucinta as relações entre turismo e o desenvolvimento como liberdade:

FIGURA 1 - O DESENVOLVIMENTO COMO LIBERDADE NO TURISMO.

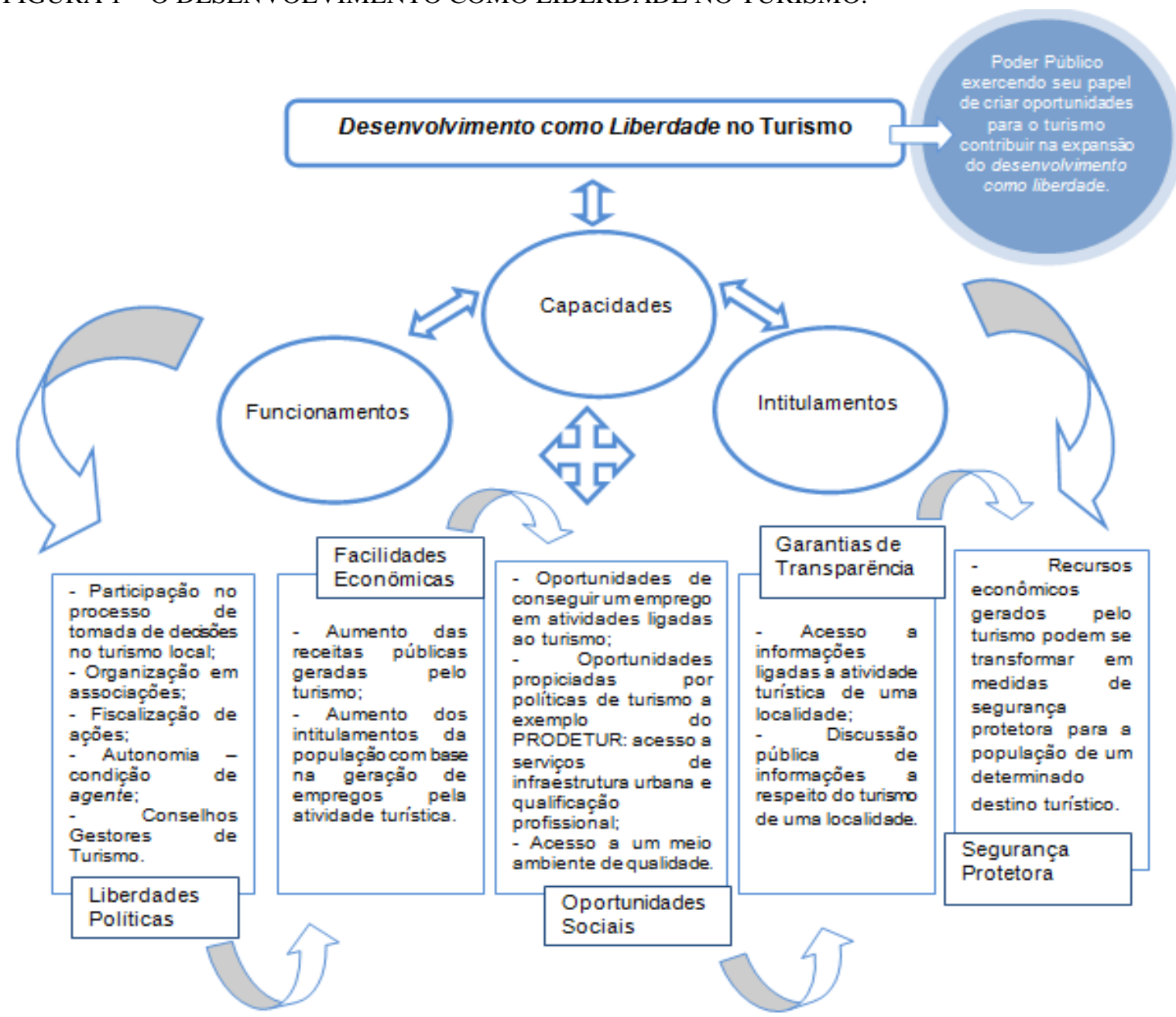

Fonte: Lima (2013).

A figura acima explicita as relações existentes entre turismo e desenvolvimento como liberdade, estando todos os itens inter-relacionados, tendo em vista que as liberdades são os principais meios e fins do desenvolvimento. O fio condutor de análise é que o desenvolvimento deve gerar liberdades, que por sua vez, geram mais desenvolvimento. Os três conceitos Sennianos centrais: funcionamentos, tudo que se considera valioso fazer ou ter; intitulamentos, pacotes de bens os quais as pessoas têm condições de adquirir mediante canais legítimos; e as capacidades, enquanto liberdade para ter estilos de vida diversos; são conceitos intimamente relacionados e podem ser 
expandidos, em alguma medida, pela atividade turística. O que se procurou mostrar até aqui é que esse processo é coletivo, sendo o incentivo do poder público, a participação popular e as políticas públicas peças chaves desse percurso.

\section{ALGUMAS CONSIDERAÇÕES FINAIS}

Entender e trabalhar em prol do que se espera e do que se quer com a atividade turística para uma determinada comunidade, é o primeiro passo para que esta se constitua com potencialidade para a transformação social. Pois, ao contrário do que se imagina, o turismo não é tão negativo quanto os que acreditam que o turismo é nocivo para os territórios, nem é tão positivo, quanto à prática discursiva hegemônica ligada à atividade dá a entender. Sucintamente, ele é o resultado das relações de poder estruturadas em âmbito local, podendo ser muito positivo ou muito negativo, dependendo da forma como será conduzido pelos atores sociais ligados à atividade.

Nesse sentido, objetivou-se nesse artigo elencar aspectos significativos que devem ser levados em consideração na atividade turística para que essa venha a contribuir com a melhoria da qualidade de vida das pessoas, isto é, como indutora de um processo de desenvolvimento. Levando em consideração que a discussão do binômio turismo e desenvolvimento deve analisar aspectos para além dos indicadores econômicos, devendo incluir a consideração de elementos qualitativos necessários a um processo positivo de transformação social (educação, saúde, oportunidades sociais diversas, entre outros).

No percurso teórico, realizou-se à articulação da perspectiva do desenvolvimento como liberdade, do autor indiano Amartya Sen, com a atividade turística, no qual se considerou a possibilidade de cada liberdade instrumental (Liberdades Políticas, Facilidades Econômicas, Oportunidades Sociais, Garantias de Transparência e Segurança Protetora), conforme pensadas por Sen (2000), serem incentivadas/fortalecidas pelo turismo. Chegando-se à conclusão, que mesmo de forma indireta, a atividade turística pode incentivar as liberdades instrumentais analisadas.

Com relação a isso, são os diversos atores vinculados à gestão pública, à iniciativa privada, à sociedade civil e à população de um local, que devem atuar em 
cooperação, buscando aumentar as chances de um turismo capaz de diminuir privações da população. Sendo imprescindível, à atuação do poder público, como articulador das ações, do incentivo à condição de agente das pessoas, para que estas possam se colocar e atuar conjuntamente na escolha dos caminhos que serão trilhados em busca do desenvolvimento como expansão das capacidades e liberdades dos indivíduos.

\section{REFERÊNCIAS}

ALMEIDA, J. A problemática do desenvolvimento sustentável. In: BECKER, D. F. (org). Desenvolvimento sustentável: necessidade e ou possibilidade? Santa Cruz do Sul: EDUNISC, 2001.

AGUIAR, G. M. de. Turismo, desenvolvimento local e integração regional. In: SEABRA, G. Turismo de base local: identidade cultural e desenvolvimento. João Pessoa: Editora Universitária UFPB, 2007.

BNB. Relatório Final - Programa de Desenvolvimento do Turismo no Nordeste Primeira Fase. Fortaleza, 2005.

BENI, M. C. Planejamento estratégico e gestão local/regional do turismo. In: SEABRA, G. Turismo de base local: identidade cultural e desenvolvimento. João Pessoa: Editora Universitária UFPB, 2007.

BRESSER PEREIRA, L. C. Sociedade Civil: sua democratização para a Reforma do Estado. In: Sociedade e estado em transformação. BRESSER PEREIRA, L. C.; WILHEIM, J.; WILHEIM, J.; SOLA, L. (org.). São Paulo/SP: UNESP, 1999.

BUARQUE, S. C. Turismo, solidariedade e inclusão. In: Diálogos do Turismo - uma viagem de inclusão. Ministério do Turismo, Instituto Brasileiro de Administração Municipal. Rio de Janeiro: Ed. IBRAM, 2006, p. 76-85.

Construindo o desenvolvimento local sustentável: metodologia de planejamento. Rio de Janeiro: Editora Garamond, 2008.

CMMAD - COMISSÃO MUNDIAL SOBRE MEIO AMBIENTE E DESENVOLVIMENTO. Nosso futuro comum. Relatório Brundtland. Rio de Janeiro: Fundação Getúlio Vargas, 1988.

COSTA, J. B. A. da. A ressignificação do local: o imaginário político brasileiro pós- 80 . Revista São Paulo em Perspectiva. São Paulo: Fundação SEADE, v. 10, n. 03, jul./set. 1996.

CRUZ, R. C. Política de turismo e território. 2. ed. São Paulo: Contexto, 2001. 
DOWBOR, L. Desenvolvimento local e apropriação dos processos econômicos. In: Revista IEB, n. 50, set./mar., 2010, p. 13-112.

FONSECA, M. A. P. da. Espaço, políticas de turismo e competitividade. Natal: EDUFRN, 2005.

FURTADO, C. O mito do desenvolvimento econômico. 4. ed. Rio de Janeiro: Paz e Terra, 1974.

GOHN, M. da G. Conselhos Gestores e Participação Sociopolítica. São Paulo: Cortez, 2001.

GREEN, D. Da Pobreza ao Poder: como cidadãos ativos e estados efetivos podem mudar o mundo. São Paulo: Cortez, 2009.

INSTITUTO ECOBRASIL. Turismo de Base Comunitária TBC. (s./d.). Disponível em: <http://www.ecobrasil.org.br>. Acesso em: 18/02/2012.

PUTNAM, R. D. Comunidade e democracia: a experiência da Itália Moderna. Rio de Janeiro: Ed. Fundação Getúlio Vargas, 1996.

LIMA, R. M. M. de. Política de Turismo e Desenvolvimento: uma avaliação do PRODETUR II em Parnamirim/RN (2005-2012). Rio Grande do Norte, 2013. Dissertação (Mestrado em Ciências Sociais). Departamento de Ciências Sociais, Universidade Federal do Rio Grande do Norte.

RODRIGUES, A. B. Percalços do Planejamento Turístico: O PRODETUR-NE. In: RODRIGUES, A. B. (org.). Turismo e Geografia: reflexões teóricas e enfoques regionais. 2. ed. São Paulo: Hucitec, 1999.

RUA, M. G. Turismo e Políticas Públicas de Inclusão. In: Diálogos do Turismo - uma viagem de inclusão. Ministério do Turismo, Instituto Brasileiro de Administração Municipal. Rio de Janeiro. Ed. IBRAM, 2006, p. 16-37.

SEN, A. K. The Concept of Development. In: CHENERY, H.; SRINIVASAN, T. H. (Eds.). Handbook of Development Economics, v. 1. Amsterdam: North-Holland, 1988, p. 10-26.

A ideia de justiça. São Paulo: Companhia das Letras, 2011.

Desenvolvimento como liberdade. São Paulo: Companhia das Letras, 2000.

O Desenvolvimento como expansão de capacidades. Revista Lua Nova, n. 2829. São Paulo: CEDEC, p. 313-333, 1993.

SOUZA, M. L. de. O subdesenvolvimento das teorias do desenvolvimento. Revista Princípios, São Paulo, v. 35, p. 27-33, 1994. 
A teorização sobre o desenvolvimento em uma época de fadiga teórica, ou: sobre a necessidade de uma "teoria aberta" do desenvolvimento sócio-espacial. Revista Território, Rio de Janeiro, v. 1, n. 1, p. 5-23, 1996.

ZAPATA, T. R.; ZAPATA, J. C. Turismo, Valorização da Brasilidade e Construção do Capital Social. In: Diálogos do Turismo - uma viagem de inclusão. Ministério do Turismo, Instituto Brasileiro de Administração Municipal. Rio de Janeiro. Ed. IBRAM, 2006, p. 38-75.

Recebido em: 30-09-2013.

Aprovado em: 30-10-2013. 